\title{
Erratum to: Measuring corruption in Europe: public opinion surveys and composite indices
}

\author{
Kristyna Chabova ${ }^{1}$
}

Published online: 19 July 2016

(C) Springer Science+Business Media Dordrecht 2016

\section{Erratum to: Qual Quant DOI 10.1007/s11135-016-0372-8}

Unfortunately, an article note was incompletely published in the original article. The complete article note is provided in this erratum.

This paper was supported by the grant of the Ministry of Education, Youth, and Sports nb. LM2015066 and by GAUK nb. 38915 (Charles University).

The online version of the original article can be found under doi:10.1007/s11135-016-0372-8.

Kristyna Chabova

Kristyna.chabova@gmail.com

1 Institute of Sociology, Czech Academy of Sciences and Charles University,

Prague, Czech Republic 